Marquette University

e-Publications@Marquette

College of Education Faculty Research and

Publications

Education, College of

$10-1-2012$

\title{
¡Vamos! How School Leaders Promote Equity and Excellence for Bilingual Students
}

Martin Scanlan

Marquette University, martin.scanlan@marquette.edu

Francesca A. Lopez

Marquette University, francesca.lopez@marquette.edu

Accepted version. Educational Administration Quarterly, Vol. 48, No. 4 (October 2012): 583-625.

DOI. (C) 2012 SAGE Publications. Used with permission. 
Marquette University

\title{
e-Publications@Marquette
}

\section{Education Faculty Research and Publications/College of Education}

This paper is NOT THE PUBLISHED VERSION; but the author's final, peer-reviewed manuscript.

The published version may be accessed by following the link in the citation below.

Educational Administration Quarterly, Vol. 48, No. 4 (October, 2012): 583-625. DOI. This article is (C) SAGE Publications and permission has been granted for this version to appear in ePublications@Marquette.SAGE Publications does not grant permission for this article to be further copied/distributed or hosted elsewhere without the express permission from SAGE Publications.

\section{¡Vamos! How School Leaders Promote Equity and Excellence for Bilingual Students}

\author{
Martin Scanlan \\ College of Education, Marquette University, Milwaukee, WI \\ Francesca López \\ College of Education, Marquette University, Milwaukee, WI
}

\begin{abstract}
Background: Focusing on culturally and linguistically diverse students, this article presents a narrative synthesis of empirical evidence guiding school leaders to promote educational equity and excellence.

Research Design: This study employs a tripartite theoretical model that emphasizes cultivating language proficiency, providing access to high-quality curriculum, and promoting sociocultural integration. Using this as an organizing framework, the article presents a review of 79 empirical articles published from 2000 to 2010.

Findings: The article explains how school leaders can use research literature to craft effective and integrated service delivery for their culturally and linguistically diverse students.
\end{abstract}

Keywords bilingual, cultural diversity, linguistic diversity, school leadership, service delivery 
Inequitable educational opportunities persist (Borman \& Dowling, 2010), and the evidence of ubiquitous injustice can leave one nauseated, cynical, frustrated, and overwhelmed. This article interrupts the abundance of literature admiring problems by focusing instead on countervailing evidence, reasons for hope. Focusing on culturally and linguistically diverse students, we synthesize empirical evidence guiding school leaders to promote educational equity and excellence.

We know that school leaders facilitate school improvement (Boscardin, 2005; Hallinger \& Heck, 1998; Waters \& Grubb, 2004). Successful principals set the direction in the school by articulating a shared vision, modifying organizational structures to support a culture and practices that reflect this vision, and building the capacity of the school to enact this vision by fostering professional growth (Drago-Severson, 2007; Wallace Foundation, 2008). School leadership is not simply positional (e.g., wrapped up in the principal) but instead is most efficacious when distributed among various individuals (Brooks, Jean-Marie, Normore, \& Hodgins, 2007; Marks \& Louis, 1999; Spillane, Halverson, \& Diamond, 2001, 2004). Moreover, school leadership facilitates school improvement through specific foci, driving effective change that expands student learning by (a) ensuring robust curriculum, instruction, and assessment; (b) building the professional capacity of teachers and staff; (c) crafting student-centered learning environments; and (d) cultivating strong school-community relations (Bryk, Sebring, Allensworth, Luppescu, \& Easton, 2010).

Perhaps the fundamental measure of success for school leaders is the academic success of traditionally marginalized students (Brooks et al., 2007; Frattura \& Capper, 2007; Marshall \& Oliva, 2006). Students from culturally and linguistically diverse (CLD) families remain among the most marginalized in schools. ${ }^{1}$ For instance, CLD students who are English language learners (ELLs) are significantly less likely than other students to score at or above a basic level of achievement in reading and math (Fry, 2007). Moreover, CLD students have less access to high-quality teachers, instructional time and materials, appropriate assessments, and adequate educational facilities (Alemán, 2007; Gandara, Rumberger, Maxwell-Jolly, \& Callahan, 2003). The language assessments commonly used with these students are suspected to incorrectly identify language abilities (MacSwan \& Rolstad, 2006), contributing to disproportionately high disability labeling (Artiles, 2003; Artiles, Rueda, Salazar, \& Higareda, 2005). To exacerbate the situation, this population is growing dramatically more than other racial and ethnic groups (Garcia \& Cuellar, 2006; National Center for Education Statistics, 2010). Public school enrollment of White students has declined whereas the enrollment of CLD students has grown (see $\underline{\text { Table } 1}$ ).

Table I. Trends and Distribution of Students by Race and Ethnicity

\begin{tabular}{|c|c|c|c|c|}
\hline & \multicolumn{2}{|c|}{ Overarching Trend } & \multicolumn{2}{|c|}{ Geographical Distribution } \\
\hline & $2001(\%)$ & $2008(\%)$ & $\begin{array}{l}\text { Suburban or } \\
\text { Rural }(\%)\end{array}$ & Urban (\%) \\
\hline White & 61 & 56 & 66 & 17 \\
\hline Hispanic & 17 & 21 & 46 & 45 \\
\hline Asian or Pacific Islander & 4 & 5 & 53 & 42 \\
\hline Black & 17 & 17 & 45 & 47 \\
\hline $\begin{array}{l}\text { American Indian or } \\
\text { Alaska Native }\end{array}$ & 1 & 1 & 57 & 20 \\
\hline
\end{tabular}

Source: Adapted from National Center for Education Statistics (2010, Tables 7.1-7.2). 
Addressing this confluence of inequities is a pressing concern at both the building level, where schools are sanctioned when they fail to make adequate yearly progress as defined by No Child Left Behind, and at the system level. In a recent settlement with the Departments of Justice and Education alleging civil rights violations of English-language learners, Boston public schools have committed to providing extensive compensatory services (Zehr, 2010). Yet calls to address these inequities are nothing new. More than 20 years ago, Medina (1988) noted the rapid demographic growth of Hispanic students was being met with increasing segregation within and across schools and high rates of failure and dropout, perpetuating "Hispanic economic and social apartheid" (p. 346).

Concomitantly, empirical literature has examined effective educational practices for CLD students for decades (e.g., Lucas, Henze, \& Donato, 1990) and addresses this concern from many angles. Some literature describes effective practices for educating these students by focusing on specific content areas, such as reading and writing (August \& Shanahan, 2008; Slavin \& Cheung, 2005) or science (O. Lee, Mahotiere, Salinas, Penfield, \& Maerten-Rivera, 2009). Other literature looks at specific populations of CLD students, such as those with disabilities (e.g., Rodriguez, 2009), those who are immigrants (e.g., Hernandez, Denton, \& Macartney, 2009), or those with specific ethnic and cultural identities (e.g., Garcia \& Jensen, 2007). This array of literature describing effective strategies for serving these students is robust and growing but also disparate and focused on classroom practices. Because of this, the literature frequently fails to inform in coherent service delivery decisions at the building and system levels that optimize learning for CLD students. To wit, nearly $60 \%$ of secondary school students have been designated by schools as ELLs for more than 6 years and not attained a level of proficiency to warrant reclassification (Olsen, 2010). Clearly, a large gap remains between what is known about effective practices and what is implemented in schools.

This article seeks to address this problem by synthesizing salient empirical literature to provide guidance to school leaders in their work with CLD students and families. We specifically seek to answer the following question: How does extant empirical literature guide school leaders seeking to craft effective and inclusive service delivery models for CLD students? CLD students are varied across multiple dimensions, including proficiency in English, race and ethnicity, national heritage, and socioeconomic status. We affirm this pluralism in our analysis, cognizant that school leaders are effective to the degree that they attend to these multiple dimensions.

In the education of CLD students, perspectives toward native language have historically shifted from seeing it as a problem, a right, and a resource (Salomone, 2010). In this synthesis, we approach language as a resource. We recognize that this perspective is contested. Salomone (2010) describes the paradox:

"Language is now viewed socially and politically as both a skill of international necessity and a symbol of national threat, especially when that language is Spanish or Arabic" (p. 12). Thus, much of schooling involves subtractive approaches to remove language from CLD students alongside additive approaches to foster bilingualism among native English speakers. By contrast, our synthesis of empirical literature regarding effective and inclusive service delivery models is explicitly asset oriented, seeing language as a resource to foster.

\section{Our Approach to Narrative Synthesis}

Narrative synthesis is an appropriate method for systematically analyzing heterogeneous studies that present diverse forms of evidence (Popay et al., 2006; Rodgers et al., 2009). As Popay et al. 
(2006) describe, "[T]he 'defining characteristic' [of narrative synthesis] is that it adopts a textual approach to the process of synthesis to 'tell the story' of the findings from the included studies" (p. 5). This method allows us to include studies employing a range of methodologies: purely quantitative, purely qualitative, and mixed methods. Established norms of conducting narrative synthesis guided our methods (Popay et al., 2006; Rodgers et al., 2009). Narrative syntheses begin by identifying a theoretical model that guides the review. An appropriate body of empirical research is then gathered, and the relationships in the data are examined through this theoretical model. Rodgers et al. (2009) describe the final step: "[T]he analysis of relationships within and between studies described should lead into an overall assessment of the strength of the evidence available for drawing conclusions on the basis of a narrative synthesis" (p. 65). We address each of these steps in turn.

\section{Theoretical Model}

The first step in a narrative synthesis is articulating a theoretical lens. We drew on two established frameworks to guide our analysis of empirical research addressing the education of CLD students. Our core lens is integrated, comprehensive service delivery, or ICS (Frattura \& Capper, 2007). ICS articulates an approach to organizing the array of student support services (e.g., special education, bilingual or English as a second language services, counseling, title services, etc.) in a manner that prevents (not responds to) student failure and builds the capacity of teachers to anticipate and embrace diversity within learners. The theory is that the location and delivery of support services are central to educational equity: These should be integrated into the core curriculum and instruction, not divided into separate programs. In addition, structures of inclusive service delivery strive to ensure that students are distributed in natural proportions across heterogeneous settings in the school. This means that if CLD students compose $20 \%$ of the school, they should not be over- or underrepresented in various settings (e.g., advanced classes, special education identification, etc.). Four cornerstones form ICS (Frattura \& Capper, 2007). First, the core principles of service delivery must focus on providing equitable educational opportunities for all students. Second, the location and arrangement of services must structure these equitable educational opportunities. Third, the professional development and curriculum and instruction must emphasize providing access to high-quality teaching and learning for all students. Fourth, the funding and policy mechanisms must support integrating service delivery.

The theory of ICS is reflected in scholarship describing social justice leadership (Theoharis, 2007), which attributes improved student learning outcomes to school structures and cultures that explicitly reduce marginalization across multiple dimensions of diversity. In addition, ICS is congruent with analyses of organizational improvement that recognize the central role of situational characteristics. For instance, Kennedy (2010) notes that the tacit model of improving student learning frequently foregrounds the effects of teachers while downplaying or ignoring the situational characteristics that delimit teachers' practices. Similarly, ICS emphasizes how school structures (as opposed to characteristics of individual educators) shape the degree to which practices of service delivery are inclusive and equitable.

With ICS at the core, we chose a tripartite theory of effective school communities for bilingual students to guide our organization of literature. We construct this drawing directly from Brisk's (2006) description of quality schooling for CLD students, O. Lee and Luykx's (2005) theory of instructional congruence, and Haas and Gort's (2009) summary of best practices for ELLs. Brisk identifies three domains characterizing school communities that effectively educate CLD students: (a) cultivating language 
proficiency to academic grade level, (b) ensuring access to high-quality curriculum within effective teaching and learning environments, and (c) promoting the sociocultural integration of all students. In a similar manner, Lee and Luykx argue that "effective subject area instruction should consider the nature of academic disciplines in relation to students' linguistic and cultural experiences" (p. 414). Lee and Luykx emphasize that "congruence not only between students' culturally based interactional norms and those of the classroom but also between the academic disciplines and students' linguistic and cultural experiences" (p. 414). They define instructional congruence in a three-ring Venn diagram weaving English language and literacy, academic content (in their case science), and home language and culture. Finally, Haas and Gort's (2009) three principles of best practices emphasize additive approaches to language, culturally and linguistically responsive instruction, and quality instruction integrating language and content teaching:

An effective educational program ... should (a) actively and strategically build on students' native language to develop English and, whenever possible, foster the preservation of children's home language and encourage bilingualism and biliteracy among language-minority children in additive bilingual environments; (b) use culturally and linguistically responsive teaching methods and curriculum; and (c) integrate language and subject-matter content teaching through sheltered content and cognitive strategy-building instructional techniques. (p. 127)

These principles of best practices, as well as O. Lee and Luykx's dimensions of instructional congruence, directly map onto Brisk's (2006) three domains.

By emphasizing the characteristics of school communities and the conditions that promote successful learning environments for CLD students, our tripartite theory of effective schooling for CLD students applies to schools serving a range of student populations, from schools that are relatively homogenous in this regard (e.g., having a large population of native Spanish speakers) to schools that are heterogeneous (e.g., having a wide range of native languages represented in the student body). As we illustrate in Figure 1, we use these three dimensions of quality schooling for CLD students (Brisk, 2006; Haas \& Gort, 2009; O. Lee \& Luykx, 2005) to organize our narrative synthesis, placing the principles of ICS (Frattura \& Capper, 2007) at the heart of our framework. The foci of ICS (on the four areas of equity, the location and arrangement of services, access to high-quality curriculum, and funding and policy mechanisms) overlap considerably with the three dimensions of quality schooling (language proficiency, quality curriculum and instruction, and sociocultural integration). In Figure 1, we represent these three dimensions as an external frame surrounding the principals of ICS. 


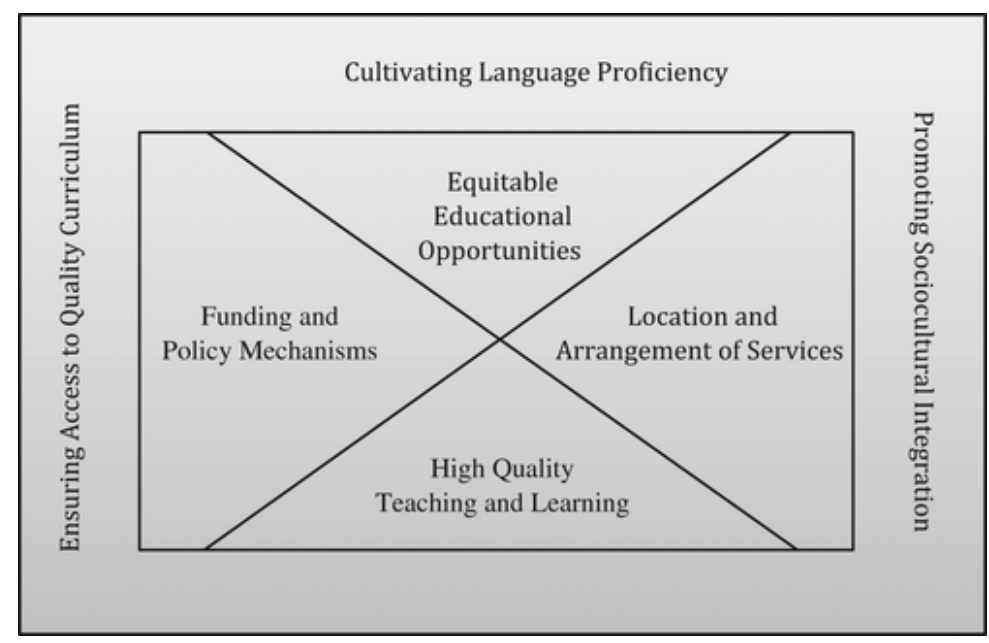

Figure 1. Theoretical model guiding effective service delivery for bilingual students

\section{Body of Empirical Research and Analysis}

After identifying a guiding theoretical framework, the second step of a narrative synthesis is to gather an appropriate body of empirical research and analyze the relationships in the data through this theoretical lens. We initially identified potential studies by searching the electronic database Educational Resources Information Center using selected keywords (English language learner, linguistically diverse, limited English proficiency, bilingual). Inclusion criteria for a work to be included in the synthesis included (a) published in peer-reviewed journals, (b) published in English, (c) published between 2000 and 2010, and (d) focused on elementary and/or secondary schools. Reports by organizations and books were excluded, as we limited our analysis to peer-reviewed scholarship. We initially read each article's abstract to determine if it was directly related to our conceptual framework. From the selected articles we then employed an ancestry approach, examining references to further identify relevant literature missed in the original search. Through this process we arrived at a final corpus of 79 articles that we include in our synthesis (see the appendix). Nearly two thirds of these are quantitative studies $(n=24)$ or qualitative studies $(n=25)$, with the remaining a mix of conceptual analyses $(n=12)$, syntheses of research $(n=11)$, and other types, such as historical analyses $(n=7)$.

We began the process of coding these sources using the three domains characterizing effective school communities for bilingual students (see Figure 1). After initially coding each article independently, we had full agreement on $81 \%$ of the coding (64 of the 79 articles). We then discussed the 15 articles on which our coding differed and mutually agreed on the codes to resolve these differences. We proceeded to collaboratively analyze each of these articles in an iterative process exploring the relationships among the findings in the studies and assessing the robustness of each. We assessed findings that appeared in multiple studies utilizing diverse methodologies to be the most compelling. Our theoretical framework focused our attention toward structuring ICS in manners to allow CLD students to (a) develop language proficiency, (b) access quality teaching and learning, and (c) experience sociocultural integration. As we analyzed the articles in each section, we paid particular attention to the four cornerstones of ICS described above (Frattura \& Capper, 2007). We report the most compelling implications within these three intersections based on the preponderance of evidence, as well as the most salient inconsistencies, within each of these three domains (see Figure 1). 
The third and final step of a narrative synthesis is assessing the strength of the available evidence and drawing conclusions based on this assessment. In the final section of the analysis we explore how school leaders at the building and system levels can use this analysis to shape decisions about bilingual service delivery in their contexts. We also make recommendations for leadership preparation programs.

\section{Relationships Across Literature}

We begin by discussing how to provide services to cultivate language proficiency in an integrated, comprehensive manner. We follow this by discussing access to a high-quality teaching and learning environment and sociocultural integration in parallel manners. As will become evident in these sections, these categories overlap one another considerably. Thus, despite the impression of neatly segmented groups, the lines dividing them should be recognized as blurred, and the dimensions interacting.

\section{Cultivating Language Proficiency}

The first goal of effective schools serving CLD students is cultivating language proficiency (Brisk, 2006; Haas \& Gort, 2009; O. Lee \& Luykx, 2005). Cultivating language proficiency intersects with crafting integrated service delivery in the realm of language acquisition models. School communities responding to CLD students and families have an array of language acquisition models from which to choose (Gandara, Moran, \& Garcia, 2004; Ovando, 2003). These models all share the goal of developing proficiency in English. Some (i.e., developmental bilingual and two-way immersion) have the additional goal of developing proficiency in a second language. Models promoting bilingualism combine instruction in both English and the first language (most typically Spanish). Models focused on cultivating monolingualism either rely solely on English for instruction (i.e., structured English immersion) or incorporate the home languages to a limited degree (i.e., transitional bilingual). Table 2 illustrates this range of models.

Table 2. Continuum of Approaches to Language Acquisition

\begin{tabular}{|c|c|c|c|c|c|}
\hline \multirow[b]{2}{*}{$\begin{array}{l}\text { Language } \\
\text { acquisition } \\
\text { model }\end{array}$} & \multirow[b]{2}{*}{ English only } & \multicolumn{2}{|l|}{ English Immersion } & \multicolumn{2}{|c|}{ Bilingual Education } \\
\hline & & $\begin{array}{c}\text { English as } \\
\text { a second } \\
\text { language }\end{array}$ & $\begin{array}{l}\text { Transitional } \\
\text { bilingual } \\
\text { education }\end{array}$ & $\begin{array}{l}\text { Developmental } \\
\text { bilingual } \\
\text { education }\end{array}$ & $\begin{array}{l}\text { Two-way } \\
\text { bilingual } \\
\text { education }\end{array}$ \\
\hline $\begin{array}{l}\text { Language of } \\
\text { instruction }\end{array}$ & English & English & Bilingual & Bilingual & Bilingual \\
\hline Goal & $\begin{array}{c}\text { English language } \\
\text { development }\end{array}$ & $\begin{array}{c}\text { English language } \\
\text { development }\end{array}$ & $\begin{array}{c}\text { English language } \\
\text { development }\end{array}$ & Bilingualism & Bilingualism \\
\hline
\end{tabular}

\section{Selecting a Model}

School leaders, who play the central role shaping the selection of a model for language acquisition, must understand the different variables that constrain their options in choosing among these models. One variable is the demographic profile of the student population, including the relative size and linguistic heterogeneity of CLD students. School leaders must consider their students' backgrounds, the degree to which different language acquisition programs can be properly implemented, and the vision and mission of the school community. Decisions regarding language acquisition models are constrained by localized political, social, and economic forces as well (Callahan, Wilkinson, Muller, \& Frisco, 2009). It is most significant that many state and federal policies pressure schools to focus solely on English language acquisition (Wiley \& Wright, 2004). 
Recognizing these constraints, school leaders need to be clear about the most educationally sound model. As de Jong (2002) emphasizes, school leaders need to make decisions based on research showing the "strength of connecting theory with decisions about program design and the implementation and importance of linking these practices with actual academic outcomes" (p. 80). One way empirical research guides school leaders to craft service delivery systems that cultivate language proficiency is by recognizing language as an asset and building on the linguistic heritages of CLD students. Simply put, from an education perspective, school leaders optimally approach language proficiency broadly by promoting bilingualism. Substantial evidence illustrates that building on students' first language promotes CLD students' development of both English language proficiency and content knowledge (Rolstad, Mahoney, \& Glass, 2005; Slavin \& Cheung, 2005). Bilingualism also positively affects cognitive development (Adesope, Lavin, Thompson, \& Ungerleider, 2010; Diaz, 1983). Moreover, since bilinguals transfer academic knowledge across languages (MacSwan \& Rolstad, 2005), instructing CLD students in their home language promotes more equitable opportunities to learn. Critically, compared with their counterparts in English-only settings, students in bilingual settings develop stronger levels of selfcompetence, one of the strongest predictors of future performance (López, 2010). As Haas and Gort (2009) summarize, "Additive bilingual environments promote the acquisition of English while fostering the continued development of the primary language. Research on effective education for ELLs indicates that bilingual instructional approaches provide the most positive student outcomes" (p. 123).

This emphasis on supporting CLD students in becoming bilingual interrupts deficit orientations toward language. The terminology used to describe these students and their schooling, Callahan (2005) argues, is neither accidental nor arbitrary, but rather focuses the orientation:

The deficit model dominates the discourse on English learners; that is, language is a liability. The terminology used to discuss English learners hinges on a shared understanding of the overarching importance of the English language and its acquisition. Terms such as English learner, LEP, sheltered English, specially designed academic instruction in English, English learner advisory committee, and English language acquisition program all define students with respect to linguistic deficiency. Constructions of English learners as deficient, bilingual programs as compensatory, and ESL classrooms as linguistic rather than academic speak to the marginalization of English learners in U.S. schools. (p. 322, italics in original)

Accordingly, when school leaders adopt language acquisition models that pursue bilingualism for CLD students, they are orienting the school toward the strengths of students in an important manner.

Since CLD students are frequently clustered into schools (Hernandez et al., 2009), many schools are well positioned to adapt models that explicitly cultivate bilingualism. The strongest of these models is dual immersion, which fosters bilingualism, strong academic achievement, and cross-cultural appreciation (de Jong, 2002; Mora, Wink, \& Wink, 2001; Senesac, 2002). An alternate approach, developmental bilingualism, operates along the same design principles as dual immersion (i.e., promoting bilingualism) but serves linguistically homogenous student populations, such as native Spanish-speaking students who have limited proficiency in English (Ovando, 2003). When comparing dual immersion and developmental bilingual approaches, students tend to be better served in developing reading and writing skills in the dual immersion approach (de Jong, 2004). In addition, dual immersion has the advantage of integrating CLD students with other student populations, whereas the developmental bilingual model, by design, exclusively serves CLD students. In general the heterogeneous grouping of students across language 
backgrounds is advantageous, allowing students to serve as "language brokers" by interpreting and translating interactions (Coyoca \& Lee, 2009). Worth noting, dual immersion models are not panaceas and can be implemented in manners that exacerbate educational inequities (Coyoca \& Lee, 2009; Scanlan \& Palmer, 2009).

The literature supports the advantages of dual immersion approaches over developmental bilingual ones. It also holds that well-designed and implemented developmental bilingual approaches support language acquisition in both English and Spanish more effectively than transitional bilingual approaches (Tong, Irby, Lara-Alecio, \& Mathes, 2008). Since bilingual approaches emphasize the nondominant language (typically Spanish) during the initial years, young CLD students in bilingual models do not show comparable progress toward English proficiency with their counterparts in monolingual models (Jepsen, 2010). These differences dissipate by fifth grade. As Haas and Gort (2009) summarize, "[T]ime spent learning the native language is not time lost in developing English. In fact, for many children, time spent in their native language is time gained on academic tasks" (p. 124).

Although the optimal way to cultivate language proficiency is via one of these models promoting bilingualism (see Table 2), this is not always feasible. As suggested earlier, myriad factors constrain the choices of school leaders among language acquisition models, including the variety of languages represented in the school body, the quantity of qualified bilingual teachers fluent in these languages, and the political climate and legislation in the area. When promoting bilingualism is not feasible, the best alternative for school leaders is promoting English proficiency while still affirming bilingualism. Monolingual approaches include sheltered instruction, structured English immersion, and English as a second language (ESL) strategies (Gandara et al., 2003; Ovando, 2003; Slavin \& Cheung, 2005). These approaches all seek to maximize use of English in the classroom and scaffold this through various types of support. Often this support includes specific time devoted to English language development, which is most effective when it is developmentally tailored to the specific students. Regardless of the model supporting language acquisition employed, linguistically responsive teaching is sine qua non.

\section{Supporting Linguistically Responsive Teaching}

Whether they are able to enact a bilingual model or constrained to a monolingual one, school leaders can affirm language as a resource and an asset by helping educators across the school community teach in linguistically responsive manners. This is important for both supporting language acquisition (the focus of this section) and accessing high-quality curriculum (which we discuss later). Core principles of linguistically responsive teaching are promoting academic English, scaffolding comprehensible input (e.g., making language meaningful and contextualized), fostering social interaction across CLD and native English-speaking students, and explicitly supporting both native language and English language skill development (Lucas, Villegas, \& Freedson-Gonzalez, 2008). We first describe the approach to language acquisition undergirding linguistically responsive teaching, then turn to applying this pedagogy.

Academic English and sociocultural approaches to language Linguistically responsive teaching recognizes that conversational communication skills differ from "academic English." Lucas and colleagues (2008) explain this distinction: "Some English learners may use their second language fluently in informal conversations but still experience considerable academic or literacy-related difficulties in school, because language varies according to the context in which it is used" (p. 362). Accordingly, school leaders must ensure that the goal of cultivating language is understood as cultivating academic English. 
The concept of academic English is widely shared but understood in somewhat contested manners (Bunch, 2006, 2010; Gersten \& Baker, 2000). Clearly, language usage differs by context. For example, language used to participate in classroom activities and discussions differs from language used to craft written reports or make formal oral presentations, and both are needed to communicate about subject matter, depending on audiences and purposes (Bunch, 2006). Reviewing literature on teaching CLD students in content areas, Janzen (2008) asserts, "As a prerequisite for instruction, teachers must thoroughly understand how the language of their disciplines construes meaning and must use academic language in clear and consistent ways in the classroom" (p. 1030). Content area assessments require substantial academic English skills (Kieffer, Lesaux, Rivera, \& Francis, 2009). Building from their review of literature, Kieffer and colleagues (2009) assert, "[A]cademic language skills and content knowledge overlap with one another to a great degree... [that] virtually all sophisticated academic tasks, such as solving complex mathematical problems or reasoning with scientific information, are mediated by language and literacy skills" (p. 1188).

The literature guides school leaders to understand that the academic-conversational binary has strengths and limitations. On one hand, it provides helpful guidance to educators in considering different registers of language that students enact and points toward the complexity of fluencies in a language. At the same time, this binary oversimplifies how language works in classrooms and schools. For example, in a study exploring language usage, Bunch (2006) found "students often seemed to be the most engaged with the core academic content and concepts of the unit" when using language that might be labeled "conversational" (p. 298). "Under the right instructional conditions," Bunch concludes, "students described as being fluent in 'conversational English' yet lacking in 'academic English' can participate successfully in challenging academic work in English" (p. 298).

School leaders are well served with a nuanced understanding on the use and acquisition of language, accepting, but not essentializing, the conversational-academic dichotomy. Hawkins (2004) describes a "[sociocultural] view of language, learning, and teaching that sees meanings and understandings constructed not in individual heads, but as between humans engaged in specific situated social interactions" (p. 15). According to this perspective, Hawkins explains, "learners are apprenticing to the requisite linguistic, academic, and social practices of schools" (p. 14) within the complex ecosystems of classrooms. This suggests that rather than thinking about fluency as a singular goal to attain, educators do well to recognize that we develop a range of fluencies within the communities of practice to which we belong:

Thus, using "language" appropriately is not just a matter of words and grammar, it is part-andparcel of a "toolkit," where multiple components must be packaged together correctly in order to be recognized (and for communication to occur successfully). And these packages represent and define our identities in specific sociocultural contexts. (p. 17)

School leaders support language acquisition, accordingly, by supporting literacies that allow CLD students to succeed in academic settings. Linguistically responsive teaching fosters these literacies (Garcia, Arias, Murri, \& Serna, 2010). While reading, CLD students struggle to simultaneously master language form (e.g., grammar and syntax) and discern meaning, a difficult balance that warrants pedagogical interventions (S.-K. Lee, 2007; Silverman, 2007; Tong, Irby, Lara-Alecio, \& Yoon, 2010). Garcia and colleagues' (2010) review of research finds that teachers develop knowledge, skills, and dispositions to provide culturally and linguistically responsive instruction through working closely 
with their students in their communities. Garcia and colleagues describe these two dimensionslanguage and culture-as entwined:

Language, culture, and their accompanying values are acquired in the home and community environment. Teachers must be aware that children come to school with some knowledge about what language is, how it works, and what it is used for; that children learn higher level cognitive and communicative skills as they engage in socially meaningful activities; and that children's development and learning is best understood as the interaction of linguistic, sociocultural, and cognitive knowledge and experiences. (p. 138)

To develop their linguistic knowledge, teachers must provide CLD students with language-related experiences. Accordingly, we turn to describing the application of linguistically responsive pedagogies.

\section{Applying linguistically responsive pedagogies}

The literature guides school leaders to help teachers apply linguistically responsive pedagogies. Regardless of the language acquisition model in the school, leaders are responsible for ensuring that teachers develop fundamental understandings of language acquisition, including the concept of academic English and the intrinsic value of native language skills (Lucas et al., 2008).

The linguistic aspects of teaching CLD students, Harper and de Jong (2009) point out, are of utmost importance. In their analysis of teacher preparation to work with these students, Harper and de Jong found,

[G]eneral concepts and skills (such as those related to a basic understanding of comprehensible input, cooperative learning and cultural sensitivity) are more easily adopted by mainstream teachers, at least initially, than language- and culture-specific knowledge and skills (such as setting language objectives and using students' funds of knowledge). (p. 146)

Professional development can support teachers' knowledge and skills on how to support language and content acquisition (O. Lee et al., 2009). Some examples of focused interventions are providing explicit vocabulary instruction (Lesaux, Kieffer, Faller, \& Kelley, 2010), supporting oral language development (Spycher, 2009), facilitating peer tutoring among students (Saenz, Fuchs, \& Fuchs, 2005), and creatively using technological resources (Foulger \& Jimenez-Silva, 2007). The literature emphasizes that highquality teaching has a profoundly positive impact on language acquisition in particular, and learning in general (Lara-Alecio, Tong, Irby, \& Mathes, 2009). Finally, attending to linguistically responsive teaching directs school leaders to ensure that CLD students have appropriate accommodations on assessments such that language proficiency levels do not impede these students from demonstrating content area knowledge (Abedi, Hofstetter, \& Lord, 2004; Kieffer et al., 2009).

When promoting linguistically responsive teaching in a school community, the literature guides school leaders to carefully consider how the language acquisition model employed in the school groups students. Providing opportunities for interaction between CLD students and their native English classmates supports the development of conversational and academic English (Bunch, 2006; Lucas et al., 2008; Saenz et al., 2005). Accordingly, language acquisition models that heterogeneously group students are advantageous. Two-way immersion, for instance, fully integrates linguistically diverse populations by design. Although variations of implementation exist, all seek to have classroom enrollments reflect a student population composed of $50 \%$ students who are native English speakers and $50 \%$ students who are native in the target language for bilingualism (typically Spanish; de Jong, 2002; Mora et al., 
2001; Senesac, 2002). Monolingual approaches that integrate bilingual students into the general education classrooms share this feature of delivering supports to CLD students inclusively, thus integrating linguistically diverse populations. However, monolingual approaches have the considerable disadvantage in that they fail to build on and affirm the home language.

Other models rely on homogenous groupings of students by language (refer to Table 2). Developmental bilingual approaches (which promote bilingualism) and transitional bilingual approaches (which promote monolingualism) both are structured in manners that educate CLD students, to some degree, in isolation. The literature points to several disadvantages of homogenous groupings. In secondary settings in particular, placing CLD students in separate classes with ESL support can inhibit their access to academic content on parity with their native English-speaking counterparts (Callahan et al., 2009). As Callahan and colleagues (2009) explain, "The most successful programs for secondary immigrant linguistic-minority students forefront access [italics added] to academic content" (p. 358). Although support services for CLD students developing English proficiency are necessary, "opportunities for [CLD] students [in ESL classrooms] . . . appear to be insufficient for academic progress at parity with mainstreamed [italics added] immigrant students" (p. 377). By contrast, some evidence suggests that developmental bilingual approaches can be designed in manners that moderate this isolation and provide substantial opportunities for social and academic integration of linguistically diverse populations (de Jong, 2006).

Some evidence suggests that on one hand, teachers are open toward including CLD students and accommodating their needs, but on another hand, they are uncertain about how to support language usage in the classroom and ambivalent about receiving professional development to support this (Reeves, 2006). This underscores the importance for school leaders of carefully building staff capacity to engage in linguistically responsive instruction and not simply placing CLD students in mainstreamed settings and leaving it at that.

An additional dimension of student grouping regards special education service delivery. CLD students who are properly identified with disabilities are best served in linguistically responsive teaching and learning environments (Rodriguez, 2009). As one case study suggests, critically considering what constitutes the least restrictive environment may lead to the conclusion that CLD students have been inappropriately excluded from the general education classroom and that with care and preparation they can be integrated well (P. Gutierrez, 2002). Compounding special education service delivery decisions is the fact that many CLD students are inappropriately placed in special education. Garcia and Cuellar (2006) note these students "appear more likely to be placed in special education as the amount of language support is reduced" (p. 2239), suggesting that monolingual models may lead to overidentification of CLD students as requiring special education. Frequently such misplacement is the result of Spanish language tests misidentifying students as limited in their home language (MacSwan \& Rolstad, 2006). School leaders, accordingly, must be especially vigilant to safeguard against inappropriate labeling. For instance, sophisticated reading comprehension assessments are now able to more accurately determine whether comprehension problems are the result of the language demands of texts or access to background knowledge instead of a more general comprehension disorder. Such distinctions have important implications for the types of interventions that schools employ. Early interventions that provide CLD students opportunities for language development have been shown to have positive impacts on learning outcomes, investment in school, and cognitive engagement as well as reduce learning disability diagnoses (Bernhard et al., 2006). 
In sum, selecting a model that supports language acquisition is a complex decision for school leaders. Supporting language acquisition, as Bunch (2006) suggests, is inextricably connected to providing access to high-quality curriculum:

In order to promote both language learning and access to subject area content ... continuing efforts are needed to envision classrooms in which students can be included in, rather than excluded from, opportunities to participate in as wide a range of English for academic purposes as possible. Classrooms ... [that increase] the linguistic and academic demands of instruction while providing support to language minority students, represent one attempt to provide such inclusion. (p. 299)

This brings us to the second component of our tripartite framework, to which we now turn.

\section{Ensuring Access to High-Quality Curriculum}

Alongside cultivating language proficiency, a second way empirical research guides school leaders to serve CLD students is crafting service delivery systems that ensure access to high-quality curriculum (Brisk, 2006; Haas \& Gort, 2009; O. Lee \& Luykx, 2005). Doing so entails fostering the skills of all teachers to help bilingual learners simultaneously develop content knowledge as well as language skills.

Regardless of the language acquisition model employed, quality of pedagogy is a core factor to quality of learning (Lara-Alecio et al., 2009). As described in the previous section, CLD students benefit from linguistically responsive teaching. We now shift our attention from how linguistically responsive teaching supports language acquisition to how it provides access to a high-quality curriculum, recognizing that these two goals have considerable overlap.

\section{Quality Teaching for CLD Students}

Fundamental principles of good teaching are a starting point for providing access to high-quality curriculum for CLD students. The literature consistently emphasizes, however, that such pedagogy has specific characteristics that focus on these students' needs. In their examination of effective instructional practices for students who are ELLs, Gersten and Baker (2000) explain this:

Principles of effective instruction for native English speakers need to be modulated for Englishlanguage learners if the simultaneous goals of English-language development and content acquisition are to be met. In other words, effective instruction for English language learners is more than just "good teaching." It is teaching that is tempered, tuned, and otherwise adjusted, as a musical score is adjusted, to the correct "pitch" at which English language learners will best "hear" the content (i.e., find it most meaningful). (p. 461)

Teacher dispositions toward accommodating CLD students are a key factor in the degree to which these students succeed (Reeves, 2006). Harper and de Jong (2009) note that many students who are ELLs are subjected to "teachers who are unprepared to meet their linguistic and cultural needs or who are not willing or motivated to alter their instruction significantly because they believe that good teaching for fluent English speakers is good teaching for all students" (p. 144). Instead, as emphasized in the preceding section, one dimension of quality pedagogy for CLD students that the literature emphasizes is that teachers must have requisite knowledge about language development. Lucas and colleagues (2008) describe this well: 
Language is the medium through which students gain access to the curriculum and through which they display - and are assessed for-what they have learned. To succeed in U.S. schools, students must be able to read academic texts in different subject areas, produce written documents in language appropriate for school (e.g., tests, stories, essays), and understand their teachers and peers-all in English. Therefore, language cannot be separated from what is taught and learned in school.... Because they are learning English while learning the content of the curriculum, the process of learning English as a second language is inextricably linked with all their school learning. For that reason, a teacher who has [CLD students] in his or her class is best equipped to teach them if he or she has knowledge of some key principles of second language learning. (p. 362)

School leaders can ensure that teachers understand language learning as a nonlinear process that develops across a range of contexts and requires support across the curriculum and that they know how different registers develop, how conversational and academic registers differ, and how students develop reading comprehension skills. Professional development in creating teaching and learning environments that scaffold second language acquisition is essential (Curran, 2003; O. Lee et al., 2009). A recent study by Cirino, Pollard-Durodola, Foorman, Carlson, and Francis (2007) points toward the relationship among teacher quality, classroom instructional variables, and language and literacy outcomes for CLD students in kindergarten:

We found significant positive relations between teacher quality and student engagement, such that higher-quality teachers had students who were more frequently judged as being on versus off task. ... There were [also] significant negative relations between teacher quality and the use of noninstructional time: teachers rated high in quality did not lose instructional time in lengthy transitions that were unrelated to reading (e.g., disciplining students, making announcements, having students line up and go to the restroom, being out of the classroom, and dispelling chaotic disruptions) but focused their energies on academic activities such as oral language development, phonemic awareness, and letter-sound instruction. (p. 359)

\section{Content Area Teachers $=$ Language Teachers}

The literature suggests that, alongside understanding language development in general, teachers need to support specific language development in their content areas (Janzen, 2008). Integrating language development into content areas involves linguistic, sociocultural, and pedagogical dimensions. The particular academic registers of different subject areas (e.g., science, mathematics, social studies) must be taught: "The academic uses of language as well as the meaning of individual words need to be explicitly taught for students to fulfill the genre or discourse requirements privileged in academic settings and to understand the material they encounter" (Janzen, 2008, p. 1030). Schleppegrell (2007), reviewing research on the linguistic challenges associated with teaching and learning mathematics, observes that "learning the language of a new discipline is a part of learning the new discipline; in fact, the language and learning cannot be separated" (p. 140). The implication is clear: School leaders must help all teachers recognize that they are language teachers.

Although classroom teachers may not have always considered educating bilingual students as a central responsibility, the accountability pressures of No Child Left Behind (NCLB) are increasingly resulting in this. Schools and districts are required to demonstrate achievement gains as measured on standardized achievement tests for students across multiple dimensions of diversity, including students with limited 
proficiency in English. They are also required to provide these students with "highly qualified teachers." These mandates often result in the placement of bilingual students who are developing proficiency in English into general education classrooms, often without the support services they might have received in other settings. Haas and Gort (2009) explain, "A major challenge of teaching English learners is the need to integrate academic content, language, and culture in every lesson" (p. 126).

In an article describing effective instructional practices for CLD students based on data from a review of research and a focus group of practitioners, Gersten and Baker (2000) characterize English language development and content area learning as "distinct educational goals" (p. 460) and that "providing time each day for English-language learners to work on ... [language development] and providing academically challenging content instruction (whether in their first language or in English) are more likely to occur when teachers take time to make goals clear and precise" (p. 460). Yet, congruent with other researchers, Gersten and Baker describe the overlap between these goals:

[CLD students] need frequent opportunities to use oral language in the classroom. Active, daily language use should be structured to include both conversation and academic discourse. ... [They] should be taught through the use [italics added] of challenging material that does not get "watered down" merely because students are not fluent in the language of instruction.... [E]xtended discourse about academic topics and briefer responses to specific questions about content are cornerstones of academic growth for English-language learners. (pp. 461, 465)

School leaders support linguistically responsive pedagogy by focusing professional development of teachers on ways to integrate content and language instruction. For instance, instructional strategies that explicitly apply theories of multiple intelligences have been shown to result in stronger learning outcomes, enthusiasm, and engagement of CLD students (Haley, 2004). Certain questioning strategies provide access to content knowledge (e.g., mathematics) more efficiently than others (Parks, 2010).

Implications for Student Grouping

The literature distinctly emphasizes the importance of linguistically responsive teaching for crafting service delivery systems that ensure access to high-quality curriculum. The policies and practices school leaders create to group CLD students directly affect whether and how linguistically responsive teaching permeates the school community. As discussed above, different language models integrate CLD students to varying degrees (see Table 2), and these groupings affect how language is acquired. These groupings also affect CLD students' access to quality curriculum. Bunch (2006), studying how language is used in different capacities in classrooms, cautions against grouping CLD students in separate rooms for instruction:

Given the wide range of ways in which language is used in academic settings, there are limits to what can be taught explicitly in separate language classrooms. Explicit focus on language is undoubtedly helpful, but as Gutierrez (1995) argues, "an abstract study of language" is no substitution for "actual use of and participation in" a community of academic discourse (p. 34). Meanwhile, in secondary settings where content instruction is available only in English, students do not have the luxury of "waiting" until their "academic English" meets an abstract standard before they engage in grade-level curriculum. (p. 299)

Bunch continues by emphasizing the vital need for school leadership that helps school communities "envision classrooms in which students can be included in, rather than excluded from, opportunities to 
participate in as wide a range of English for academic purposes as possible" (p. 299). In research reporting tracking of CLD students, Callahan (2005) explains that "many English learners find themselves enrolled in low-track curricula with limited exposure to either the content or discourse necessary to enter into higher education" (p. 321). Access to the core academic curriculum can be impeded by segregating students into ESL settings, especially in schools with small numbers of CLD students (Callahan et al., 2009).

Teachers accepting responsibility for teaching language in the content area is essential for CLD students to be successfully integrated. Although in bilingual models this is a given (Senesac, 2002), school leaders need all teachers to accept this responsibility and have the capacity to include CLD students effectively, regardless of the language acquisition model enacted. Teachers need specific pedagogical approaches to effectively provide CLD students access to the curriculum. For instance, intentional vocabulary and writing instruction in content areas (e.g., science) leads to higher academic gains in both language and content area knowledge (O. Lee et al., 2009; Spycher, 2009). R. Gutierrez (2002) found that teachers with limited knowledge of students' home language and bilingual methodologies can still be successful scaffolding students' meaning making in content areas. Gutierrez describes teachers who were successful teaching high-level mathematics to bilingual students: "In these classrooms there was explicit use of mathematical language, teachers built on knowledge domains that were already familiar to students, Spanish language was a valued resource, and individual students were active agents in the classroom" (p. 1079). It is significant that these students were integrated into the broader student body, which in this case was English dominant.

When school leaders group CLD students into mainstream classrooms, they must ensure their teachers employ targeted strategies focused on vocabulary development (Lesaux et al., 2010), writing (Foulger \& Jimenez-Silva, 2007), and integrating content-specific supports with English-language supports (O. Lee et al., 2009). As Haas and Gort (2009) summarize, strategies and techniques of sheltered content instruction present academic content in English while accommodating second-language acquisition:

Some of the techniques that characterize sheltered content instruction include the adaptation of academic content to the students' level of English-language proficiency, the use of supplementary materials to a high degree, the emphasis of key vocabulary and language development, the modification of speech to make information comprehensible to students (including sufficient wait time), the development of clear language and content objectives for each lesson, and the integration of students' background and experiences into each. (p. 126)

In addition, school leaders need to support classroom practices that are shown to promote achievement for CLD students. For instance, research suggests that peer-tutoring strategies (Gersten \& Baker, 2000), such as those focused on reading performance (Saenz et al., 2005), improve reading comprehension for bilingual students as well as their monolingual counterparts, including beneficial effects on students with learning disabilities and students who are high achievers. Bilingual students with more advanced levels of English proficiency can also serve as "language brokers" to CLD students who are less advanced, facilitating access to academic content (Coyoca \& Lee, 2009).

Teachers are more prepared to implement targeted strategies when they either have developed expertise in bilingual and bicultural education or work collaboratively with colleagues who have such expertise (Harper \& de Jong, 2009). Collaboration among general educators and colleagues with expertise in bilingual or bicultural education is a developmental process, and the effectiveness of such 
partnership depends on the attitudes, effort, achievement, and expectations of support from participants (Davison, 2006). Finally, school leaders are well served when they critically examine how CLD students are grouped in the school considering the multiple dimensions of diversity beyond language and ethnic identity, such as race, social class, and special need (Scanlan \& Palmer, 2009).

\section{Implications for Assessment}

In addition to implications for grouping, linguistically responsive teaching has implications for assessment. Teachers must also be able to effectively assess CLD students such that their developing language proficiency in English does not interfere with their demonstration of content knowledge. Teachers must provide CLD students content-specific academic language instruction to support their performance on content area assessments (Kieffer et al., 2009). In their research review, Abedi and colleagues (2004)_summarize several conclusions about assessment accommodations. They explain that "the language of assessment should match students' primary language of instruction" (p. 17). In other words, translating test items into a student's native language is not an effective accommodation if the student studied it in English. In addition, "reduc[ing] the use of low-frequency vocabulary and complex language structures that are incidental to the content knowledge being assessed" (p. 17) is an effective and valid accommodation strategy. All students (not just CLD students) are well served by "content-area assessments that use clear language and provide sufficient time for them to show what they know. In addition, customized dictionaries or glossaries can be provided for all students, regardless of their level of English language proficiency" (p. 17). Thus, the literature provides specific guidance to help school leaders ensure that CLD students not only have access to a high-quality curriculum but also are accurately assessed on their learning.

Another dimension of assessment of CLD students is with regard to special education placement. CLD students who receive less support and instruction in their native language tend to be placed in special education programs more than their counterparts in bilingual settings (Artiles et al., 2005). Artiles and colleagues' (2005) critical analysis of disproportionality in special education referrals for CLD students directs school leaders to use multiple indicators to monitor "the magnitude and nuances of placement patterns" (p. 298) and to consider the organizational factors (not just student-level factors) that affect disproportionality: "The nature and quality of the instructional program and academic and social support services (opportunity to learn) merit consideration as part of a complex whole, particularly as they affect equal educational outcomes" (p. 299).

As mentioned earlier, the accountability pressures of NCLB place particular pressure on school leaders addressing the needs of CLD students, particularly those who are ELLs. Under NCLB, student performance on annual state assessments produces the data by which a school's "adequate yearly progress" is measured (U.S. Department of Education, n.d.). Although states may accommodate students who are ELLs by providing native language versions of these assessments, all students who have been in the United States for 3 years must take the reading and language arts sections in English. Although an extensive discussion of how school leaders navigate these assessments (let alone a critique of their appropriateness; e.g., Wiley \& Wright, 2004) is beyond the scope of this article, a brief discussion of the implications of the literature on CLD students is warranted.

High-stakes assessments drive school leaders to focus on ensuring that students who are ELLs are prepared to perform these assessments in English. This pursuit should be made in the context of the broader goals of simultaneously cultivating language proficiency and ensuring access to a high-quality 
curriculum. Accordingly, student grouping and curricular decisions must be grounded in empirical literature describing best practices to meet the specific needs of students who are ELLs, described above. By contrast, when school leaders look narrowly at students' English skills, they can mistakenly pursue ineffective strategies. For instance, Harper and de Jong (2009) report that a common tactic is placing these students who are ELLs "into remedial reading classes alongside native English speakers who have been identified as poor readers" (p. 140). Such classes typically emphasize decoding and basic skills practice, not the vocabulary development and reading comprehension that students who are ELLs typically need.

As this section has shown, the literature provides clear guidance to school leaders regarding providing CLD students' access to a high-quality curriculum. We now turn to the final dimension of our tripartite framework.

\section{Promoting Sociocultural Integration}

A third way empirical research guides school leaders is to ensure the sociocultural integration of all students (Brisk, 2006; Haas \& Gort, 2009; O. Lee \& Luykx, 2005). Sociocultural influences are factors that create the context in which children live and schools operate (Bustamante, Nelson, \& Onwuegbuzie, 2009). In schools where bilingual students are integrated socioculturally, all educators accept responsibility for the language and content-knowledge development for all students. This integration runs counter to programmatic approaches that have frequently left bilingual students "on the periphery, physically and pedagogically outside the richest academic discourse" (Callahan, 2005, p. 309). School leaders who successfully work with CLD students recognize that school communities are complex social systems and that these systems shape language and literacy development (Hawkins, 2004).

The literature emphasizes that a sense of belonging is an important factor contributing to educational success in schools. In a review of literature, Osterman (2000) concludes, "Students who experience acceptance are more highly motivated and engaged in learning and more committed to school. These concepts of commitment and engagement are closely linked to student performance, and more importantly to the quality of student learning" (p. 359). Creating a sense of belonging improves selfefficacy across subjects (McMahon, Wernsman, \& Rose, 2009) - a noteworthy finding given that selfefficacy is among the most robust predictors of academic achievement.

Racial, ethnic, and cultural dimensions of identity directly affect students' experiences of schooling. Indeed, students often internalize racial strata within schools (Fergus, 2009), which can be particularly salient for bilingual students with special needs (Rodriguez, 2009). Although some bilingual approaches are grounded in language acquisition theories that create integrated contexts, they are limited in their ability to extend integration beyond the classroom (de Jong, 2006) and often omit the sociocultural perspective of learning (Hawkins, 2004). As such, leaders must consider differences among CLD students' backgrounds to be better able to create contexts that promote feelings of belonging. When differences are ignored, resulting in an emphasis in equality over equity (Reeves, 2004) and academics over cultural frames of reference (Guo, 2009; Meyer, 2000), perceptions of educational opportunity among marginalized students can be limited, further limiting a sense of belonging.

One way leaders can promote experiences of acceptance for CLD students is by ensuring that teachers provide instructional activities that place an importance on students' lives and interests (AntropGonzalez, Velez, \& Garrett, 2005). Teachers who provide students with authorship opportunities that 
allow for self-expression, for example, can create educational experiences that bridge the perceived disconnect between some students' personal lives and school (Bernhard et al., 2006).

Another way leaders can foster a sense of belonging is by integrating students' culture into school experiences, an approach referred to as funds of knowledge (Gonzalez, Rosi, Civil, \& Moll, 2001). School experiences that bridge students' home lives with their school lives have been affirmed as ways to build social capital and improve academic skills in mathematics (Gonzalez et al., 2001), science (O. Lee, 2003, 2004), and literacy (P. Gutierrez, 2002; Janzen, 2008). Funds of knowledge approaches move beyond a focus on cultural artifacts and food (Riojas-Cortez, 2001) by creating authentic, responsive partnerships with parents (Cooper \& Christie, 2005). These partnerships between home and school are particularly important given that there is often a disconnect between academic practices and their applicability to students' lives (O. Lee \& Luykx, 2005; Orellana \& Reynolds, 2008; Ro \& Cheatham, 2009). Moreover, funds of knowledge approaches address the limited knowledge of social and cultural scaffolding many teachers have (Pawan, 2008; Sleeter, 2001; Villegas \& Lucas, 2002, 2007).

School leaders play a key role in assessing and shaping the cultural competence within a school community to cultivate belonging across these dimensions. Unfortunately, a barrier to fostering the sociocultural integration of all students is the limited knowledge and skills of school leaders in fostering cultural competence across the school community. A study by Bustamante and colleagues (2009) suggested that "school leaders did not view cultural competence development as an essential leadership function, nor did they believe it was important" (p. 814). Specific tools, including cultural audits (Bustamante et al., 2009) and equity audits (Johnson \& La Salle, 2010; McKenzie \& Scheurich, 2004; Skrla, Scheurich, Garcia, \& Nolly, 2004) help school leaders grow cognizant of the inequities that CLD students experience in their schools, providing evidence to ground and guide efforts to cultivate belonging.

\section{Culturally Responsive Instruction}

In the previous two sections, we described how the literature guides school leaders to support linguistically responsive pedagogies, which support both language acquisition and access to a highquality curriculum. Here, focusing on sociocultural integration, we draw on literature describing culturally responsive instruction. Culturally responsive instruction addresses the needs of all students, affirms each student's cultural identity, and draws on students' backgrounds as an asset. O. Lee (2003) asserts that this is an essential component of instruction: "For students from diverse backgrounds, learning is enhanced, indeed, made possible, when it occurs in contexts that are linguistically and culturally meaningful and relevant to them" (p. 467). Integrating different manifestations of intelligence into instructional strategies (Haley, 2004) and employing innovative literacy development activities with young students (Bernhard et al., 2006) are some practical examples from empirical literature that reflect culturally responsive instruction. Culturally responsive instruction also entails being mindful that certain pedagogical approaches privilege linguistic heritage and background knowledge and that one must provide appropriate variation in approaches and scaffolding to students (Parks, 2010; Pawan, 2008). Curriculum and instruction are key in creating a sense of belonging for CLD students, but a focus on students' lives is insufficient in addressing inequities in schooling for bilingual students. To create a culturally responsive environment, leaders must also ensure teachers incorporate instruction that provides knowledge about how to access of majority culture to 
ameliorate issues with access and power that perpetuate inequalities among CLD students (Gandara et al., 2003; Mora et al., 2001).

Culturally responsive instruction strengthens student identity and motivation, which are of great consequence in advancing achievement of CLD students (López, 2010). Sociocultural approaches draw on families' and communities' funds of knowledge, and by engaging families, schools promote children's academic development (Gonzalez et al., 2001; P. Gutierrez, 2002; Meyer, 2000; Riojas-Cortez, 2001). Teachers, highly segregated by race and ethnicity (Frankenberg, 2008), are able to enact culturally responsive pedagogies when they receive explicit training at working with CLD students and families (Olson \& Jimenez-Silva, 2008). Schools are more effective in creating partnerships with families when they take responsibility for ensuring that parents and caregivers have opportunities to shape the agenda of these partnerships (Cooper \& Christie, 2005; Guo, 2009). Out-of-school experiences have the potential to augment the assets students bring to the classroom. For instance, Antrop-Gonzalez and colleagues (2005) found that church activities and participation in extracurricular activities promoted social capital for Puerto Rican students. In sum, the literature guides school leaders to promote school communities that normalize culturally responsive instruction, advancing the sociocultural integration of CLD students.

\section{Discussion and Conclusions}

This study has sought to describe how extant empirical literature guides school leaders seeking to craft effective and inclusive service delivery models for CLD students. Schematically, we have used this narrative synthesis to present three core dimensions to promoting effective schools for CLD studentscultivating language proficiency, ensuring access to high-quality curriculum, and promoting sociocultural integration-as encircling the integrated service delivery (see Figure 1). School leaders, specifically building-level and system-level administrators, can use these three goals to guide service delivery decisions regarding CLD students.

As we have demonstrated in this synthesis, abundant empirical literature addresses each of these three dimensions and provides direction for school leaders. Many factors at play inhibit the implementation of practices supported in this literature. Clearly, school leaders operate within a broader context that shapes and constrains their options (Wiley \& Wright, 2004). Undeniably, limited resources present barriers for school leaders. CLD students typically experience inequitable access to appropriately trained teachers who receive adequate professional development to meet their needs as well as inequitable access to quality teaching and learning environments in terms of curriculum, instructional time, and appropriate assessments (Gandara et al., 2003). Schools serving these students often face funding disparities as well (Alemán, 2007). Recognizing these constraints does not excuse school leaders from ensuring access to a high-quality curriculum but does underscore the need to be innovative and efficient in designing service delivery.

Political climate affects the school leaders as well. As Wiley and Wright (2004) observe, "Within the context of U.S. history and the preceding colonial history, racism and linguistic intolerance have often been closely linked" (p. 145). These elements can play out in state legislation targeting undocumented immigrants (e.g., Robertson, 2011) and mandating English-only instruction in schools (e.g., in Arizona, California, and Massachusetts; Wiley \& Wright, 2004). In such a charged political climate, the role of educators becomes politicized and pedagogical considerations can become conflated with political 
positions. For instance, implementing a developmental bilingual approach for students who are ELLs can be pilloried as providing special treatment for a minority group instead of applauded as a sound way to cultivate language proficiency (Ovando, 2003). Some of these contextual dimensions are beyond the control of the school, yet school leaders influence this context as well. Especially at the local level, building and district leaders have significant power in shaping the way that CLD students are perceived and embraced (Theoharis, 2007).

Perhaps the most ubiquitous factor inhibiting the implementation of the best practices for CLD students supported in empirical literature is a lack of awareness. A profound shift in demographics is resulting in many more CLD students in schools (Garcia \& Cuellar, 2006; National Center for Education Statistics, 2010). Leadership preparation programs and professional development for practitioners lag considerably behind this shift, resulting in an abundance of school leaders underprepared to serve these students. Accordingly, in this final section we describe key implications of the literature for these leaders. We first employ a narrative style to illustrate how a school principal might optimally approach CLD students. We then discuss recommendations for future scholarship and leadership preparation.

\section{Building-Level Narrative}

The following represents a fictional narrative of a school principal reflecting on how she attempts to apply the tripartite model of effective schooling for CLD students:

In our school community we approach educating our culturally and linguistically diverse students as an opportunity and an obligation. We are committed to embracing all students as integral members of our community, and strive to craft teaching and learning environments that reflect this commitment. Our middle school has a population of 450 students in Grades 6-8, which we split into three "houses." A quarter of our students (113 of 450) are CLD students with limited proficiency in English. Since 80\% of these students (90 of the 113 students) come from homes in which Spanish is the primary language spoken, and most would consider the ability to be fluently bilingual in Spanish and English better than solely gaining fluency in English, we have integrated a dual language option in our school. All students who are native in Spanish have the opportunity to opt into the dual language option, and a balanced number of students who are native in English are also allowed to join. As a result, the vast majority of our Latino students with Spanish heritage ( 81 of these 90 students), joined by 80 native English-speaking students, belong to our Bilingual House.

Students in the Bilingual House receive the same curriculum as their monolingual classmates in the other two houses. They receive language arts, literature, and social studies instruction in Spanish and the remainder of their coursework in English. This Bilingual House effectively communicates to the entire school community the importance of fostering bilingualism. Participants in the Bilingual House are excused from the foreign language course requirement that their classmates in the other two houses have. In the Bilingual House, CLD students with limited proficiency in English are fully integrated with their native English housemates for all courses, save a supplemental English language development course that they receive if needed. This integration promotes strong sociocultural integration of the Latino students by fostering cross-cultural and cross-linguistic relationships. The teachers in the Bilingual House have developed mastery in providing linguistically responsive instruction and serve as faculty mentors to their colleagues in other houses in this regard. 
Although the dual language approach in our Bilingual House accommodates the vast majority of our CLD students who are developing proficiency in English (71\%, or 81 of our 113 students), we have 32 students who require language support who are not included. Of these students, 9 speak Spanish but have not chosen the dual language model. The remaining 23 are from nonSpanish-language heritages, primarily Hmong (15 of the 23). The remaining students are from assorted cultural and language heritages (e.g., two siblings recently immigrated to the United States from Somalia, and one child was born in Russia and adopted into a native Englishspeaking family when she was six years old). All 23 of these students are developing proficiency in English, particularly in academic English, as evidenced by the English language proficiency assessment (Gottlieb, 2004). A dual language program is not feasible for these students because of various factors (e.g., limited numbers of speakers of any one native language, lack of native language instructors, lack of interest among native English speakers in learning the language). Accordingly, we have taken other steps to cultivate language proficiency, ensure access to the core curriculum, and foster their sociocultural integration.

Since 161 of our 450 students are in the Bilingual House, these 32 students compose $11 \%$ of the remaining student body (32/289). We proportionately distribute these students across the two remaining houses, but in an intentional manner. All $15 \mathrm{Hmong}$ students are placed in one house (Anderson House, 140 students), and the remaining 18 students are in the other (Zephyr House, 149 students). This grouping allows us to target some specific supports to the Hmong students while still proportionately distributing these students. In the Anderson House, we have worked with a community liaison to create a bilingual support program after school to foster literacy in Hmong. In both the Anderson and Zephyr Houses, CLD students are integrated into all subject areas with their native English-speaking classmates, and a bilingual resource teacher partners with the subject area teachers to provide consultation on teaching English literacy in these content areas and promote linguistically responsive instruction. We are partnering with a local university to subsidize three of our content area teachers from these two houses as they return to get their bilingual-bicultural certification, further bolstering our teachers' skills in this area. Students who are Levels 1-4 on their English language proficiency assessment (Gottlieb, 2004) take an English language development course, provided in place of the foreign language requirement. This scheduling allows us to provide these students supplementary support while simultaneously minimizing the periods of time that the students are separated from their monolingual peers.

This narrative illustrates several dimensions of the tripartite framework presented in this article. First, the language acquisition is cultivated in a manner that affirms bilingualism both directly (via the dual immersion model) and indirectly (via the heritage language supplemental classes for Hmong). In addition, linguistically responsive teaching is supported through teacher training and student grouping, structuring the students such that all teachers are accountable for supporting their learning. All students are provided access to the same curriculum, attending core content areas in the bilingual setting (Bilingual House) or monolingual setting (Anderson and Zephyr Houses). Teachers across all three houses are expected to engage in culturally responsive teaching, as all teachers have CLD students.

An important element that the narrative illustrates is the intentionality of grouping students across houses that incorporates, but also complicates, the principle of proportional distribution of students that Frattura and Capper (2007) present. The principle of proportionality holds that students should be 
distributed across the school community in a manner that is proportionate to the population. A direct application of this principle would hold that since $25 \%$ of the students in the school are developing English proficiency, these students should be equally distributed across the three houses. Instead of this direct application, the school design clusters more than $70 \%$ of these students ( 81 of 113 ) into a bilingual setting that affirms their home language (Spanish) while still providing them access to the same quality curriculum of their monolingual counterparts. This innovative approach allows the school community to affirm bilingualism as an asset and integrate 80 native English-speaking students with their CLD classmates in a much more explicit manner than might otherwise take place. (By contrast, a developmental bilingual approach could foster bilingualism for these 81 Latino students, but in a manner that isolates them from the rest of the school.)

In addition, rather than clustering the remaining 32 students into one house, the school leader uses the principle of proportionality to integrate them across the rest of the school community. Without the clear guidance of a theory, this school leader might have decided to cluster the students into one house, disproportionately raising the population of that house to $22 \%$ CLD students developing proficiency in English. As the literature review presented in this article illustrates, such grouping would not be well supported by empirical literature. For instance, it would likely diminish the opportunities for integration of CLD students with native English-speaking peers, limit their access to the same curriculum as these peers, and isolate them in the school. By instead spreading these students across the Anderson and Zephyr Houses equitably, the principal ensures that teachers across the school are responsible to both support language acquisition and provide access to the curriculum and that the students are integrated into the whole school.

\section{Implications for Scholarship and Leadership Preparation}

Recommendations emerge from this narrative review for future scholarship and leadership preparation. Relative to the goal of language acquisition, more empirical studies are needed examining how to promote language acquisition for bilingual students from diverse linguistic backgrounds in integrated manners. Research describes the theoretical bases and relative effects of different language acquisition methodologies but does not examine the structural dimensions to promoting language acquisition. These are central concerns for school leaders. Operationally, how do schools support language acquisition in manners that do not segregate bilingual students, particularly at the secondary level and with multilingual heterogeneity? How do school leaders-both preservice and practitioners-gain the requisite knowledge of language acquisition that will allow them to provide supervision and foster the professional development of their faculty in providing linguistically responsive instruction? How can districts collaborate with local institutes of higher education to provide this support, and how can faculty in departments of educational leadership work with linguists and foreign language colleagues to integrate such supports into their leadership preparation programs?

Relative to the goal of academic achievement, the literature describes the pedagogical knowledge and skills that general education teachers need to serve bilingual students but does much less to unpack the most effective ways to scaffold this at the preservice and practitioner stages. What is the relative importance of the various teacher-related factors involved, such as knowledge of language acquisition, asset versus deficit orientations toward bilingual learners, and competence in linguistically and culturally responsive pedagogies? How do educators develop and then apply knowledge of the language of content areas (e.g., the language of mathematics, the language of science) to better serve bilingual 
students? Scholarship can guide departments of education in institutes of higher education to better support the development of such teachers by prioritizing bilingual and bicultural certification of general education teachers, emphasizing the connection of language development and content knowledge within methods courses, and ensuring that fieldwork opportunities include CLD students.

Relative to the goal of sociocultural integration of students, although there is a deep body of literature examining the ways sociocultural elements of schooling can improve academic outcomes for CLD students, the body of literature tends to be "overwhelmingly based on case study approaches and ethnographic or other qualitative methods" (Goldenberg, Rueda, \& August, 2008, p. 107). As such, there remains a paucity of research that provides evidence of an explicit linkage between culturally responsive instruction and student outcomes. Without a quantitative link between sociocultural elements of schooling and student outcomes, researchers assert that the literature on sociocultural elements of schooling will be unable to contribute to policy debates centered on CLD students. Sleeter asserts, "Ethnographic work may be ignored in policy debates when ethnographers do not speak to the language of power. Currently that language is achievement test scores" (as cited in Goldenberg et al., 2008, p. 117). To address these issues, the National Literacy Panel on Language Minority Children and Youth (Goldenberg et al., 2008) recommended that future studies demonstrate the extent to which culturally responsive instruction is explicitly related to student literacy outcomes (p. 119). School leaders would be well served by an observation protocol that helps them assess levels of culturally responsive instruction in a similar manner to other dimensions of pedagogy (Pianta \& Hamre, 2009).

The narrative review we present has several limitations. It is most significant that by focusing on literature in peer-reviewed journals, we ignored a wide array of reports and books that guide school leaders seeking to craft effective and inclusive service delivery models for CLD students. In addition, by attempting to incorporate a breadth of literature relating to the three dimensions of our framework, we have sacrificed going into any of the three dimensions in greater depth. As such, this article should serve to whet the appetite of school leaders for further exploration in each of the three dimensions.

In conclusion, the goal of crafting effective and inclusive service delivery for CLD students is widely espoused yet infrequently attained. Though work always will remain to strengthen the knowledge base for reaching this goal, school leaders cannot claim that empirical research is ambiguous about the means toward this end. The way is clear: Cultivate language proficiency, provide access to high-quality teaching and learning, and promote the sociocultural integration of all students. ¡Vamos! 


\section{Appendix}

Arteles Lncluded in Norrothe Smothess

\begin{tabular}{|c|c|c|c|c|}
\hline 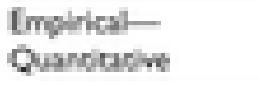 & $\frac{\text { Amplint }}{\text { Aullath }}$ & Comotoual & 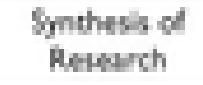 & Ditwr \\
\hline Lopar solo & 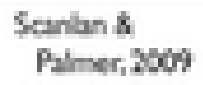 & Curra, 205 & $\begin{array}{l}\text { Abrd ce all } \\
\text { Dht }\end{array}$ & $\begin{array}{l}\text { Gandara at al. } \\
\text { 2044 }\end{array}$ \\
\hline Artht at 2005 & Alemdn 2007 & $\begin{array}{l}\text { Gared ef all } \\
2010\end{array}$ & $\begin{array}{l}\text { Adtrtst } \\
\text { at } 201,2010\end{array}$ & $\begin{array}{l}\text { Garea } 8 \\
\text { Surtlar, } 1005\end{array}$ \\
\hline Aug-it \& HL 2006 & $\begin{array}{l}\text { Antrep- } \\
\text { conriles } \\
\text { at } 2405\end{array}$ & Howhes 2004 & $\begin{array}{l}\text { Gerien } \\
\text { Buher } 2600\end{array}$ & $\begin{array}{l}\text { Has \& Gork } \\
2009\end{array}$ \\
\hline $\begin{array}{l}\text { Eerchurd et il, } \\
\text { Nos }\end{array}$ & $\begin{array}{l}\text { Butamane } \\
\text { callys }\end{array}$ & $\begin{array}{l}\text { Luen al il } \\
\text { 2009 }\end{array}$ & Jinech 200 & $\begin{array}{l}\text { Hareer } 8 \text { de } \\
\text { phe not? }\end{array}$ \\
\hline Culluhan 2005 & Burht,200t & $\begin{array}{l}\text { OLet L } \\
\text { Luph, 100S }\end{array}$ & $\begin{array}{l}\text { Retler at il. } \\
\text { Mhs }\end{array}$ & 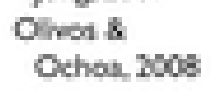 \\
\hline $\begin{array}{l}\text { Chllwin and } \\
\text { 2009 }\end{array}$ & 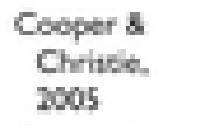 & $\begin{array}{l}\text { Mosmin } \\
\text { Polsud } \\
\text { 200s }\end{array}$ & O.Let,2003 & Owands, 109 \\
\hline Crime at, 2007 & $\begin{array}{l}\text { Coptes } \\
\text { Let, 20A }\end{array}$ & $\begin{array}{l}\text { Musmin } \\
\text { Fisud } \\
\text { 2obt }\end{array}$ & $\begin{array}{l}\text { DHemby } \\
2 \mathrm{~N}\end{array}$ & $\begin{array}{l}\text { Whys } \\
\text { Wrighe } 2004\end{array}$ \\
\hline de port $\mathbf{~} \mathbf{n}$ & $\begin{array}{l}\text { Drisat, } \\
\text { Mof }\end{array}$ & Mher, 200 & $\begin{array}{l}\text { Foluted at al. } \\
\text { Mos }\end{array}$ & \\
\hline de pry 200 & de fort 200 s & $\begin{array}{l}\text { Moriet il. } \\
\text { 201 }\end{array}$ & $\begin{array}{l}\text { Schepted } \\
201\end{array}$ & \\
\hline Fru-bonber 200: & Ferg-s.200 & $\begin{array}{l}\text { Rodrigrt } \\
\text { 20p }\end{array}$ & $\begin{array}{l}\text { Shris b } \\
\text { Chewe } \\
\text { 205 }\end{array}$ & \\
\hline $\begin{array}{l}\text { Guturi et al } \\
2003\end{array}$ & 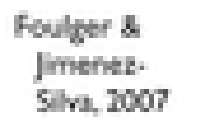 & $\begin{array}{l}\text { Ylews } 4 \\
\text { Luar, } 7007\end{array}$ & Itere 2001 & \\
\hline $\begin{array}{l}\text { Hemulte et il. } \\
2005\end{array}$ & $\begin{array}{l}\text { Gombr } \\
\text { ablal }\end{array}$ & $\begin{array}{l}\text { Yheps } 5 \\
\text { Luas, } 2007\end{array}$ & & \\
\hline Manzolo & Go.20 & & & \\
\hline Kim bjare now & $\begin{array}{l}\text { Porihrez } \\
\text { not }\end{array}$ & & & \\
\hline 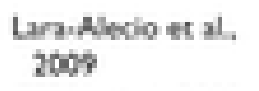 & $\begin{array}{l}\text { R. Guritez } \\
201\end{array}$ & & & \\
\hline O Len at. JoO & Hoy Juts & & & \\
\hline S.K Let, $10 \mathrm{st}$ & 0 Let, 201 & & & \\
\hline $\begin{array}{l}\text { Muthon at all } \\
2009\end{array}$ & $\begin{array}{l}\text { Letume et if. } \\
2010\end{array}$ & & & \\
\hline Pheth 004 & $\begin{array}{l}\text { Droluns } \\
\text { Prmits } \\
20 \text { s }\end{array}$ & & & \\
\hline Ah+1h Jo4 & Phh Jut & & & \\
\hline 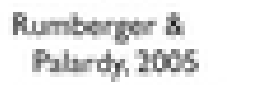 & Prtan Nox & & & \\
\hline Sutre th il, 2005 & $\begin{array}{l}\text { Rshiperte } \\
201\end{array}$ & & & \\
\hline Axman 2007 & $\begin{array}{l}\text { Rot } \\
\text { Cheathm. } \\
200\end{array}$ & & & \\
\hline Tong a d 3004 & Hrust: & & & \\
\hline Tors as soid & Sprher, 2009 & & & \\
\hline
\end{tabular}




\section{Declaration of Conflicting Interests}

The author(s) declared no potential conflicts of interest with respect to the research, authorship, and/or publication of this article.

\section{Funding}

The author(s) received no financial support for the research, authorship, and/or publication of this article.

\section{Notes}

1.Labels matter. Here we discuss students from culturally and linguistically diverse families as "CLD students" in an effort to emphasize the interplay of language and culture in identity and in the educational endeavors. When speaking about CLD students who have limited proficiency in English, we discuss these students as "English language learners." However, we acknowledge that insofar as this label implicitly emphasizes proficiency in only one language, it is deficit oriented. Therefore, throughout this article we emphasize the importance of CLD students cultivating bilingualism: language proficiency in both English and their native language.

\section{References}

Abedi, J., Hofstetter, C. H., Lord, C. (2004). Assessment accommodations for English language learners: Implications for policy-based empirical research. Review of Educational Research, 74, 1-28.

Adesope, O. O., Lavin, T., Thompson, T., Ungerleider, C. (2010). A systematic review and meta-analysis of the cognitive correlates of bilingualism. Review of Educational Research, 80, 207-245.

Alemán, E. (2007). Situating Texas school finance policy in a CRT framework: How "substantially equal" yields racial inequity. Educational Administration Quarterly, 43, 525-558.

Antrop-Gonzalez, R., Velez, W., Garrett, T. (2005). ¿Donde estan los estudiantes Puertorriquenos/os Esitosos? [Where are the academically successful Puerto Rican students?]: Success factors of high-achieving Puerto Rican high school students. Journal of Latinos and Education, 4, 77-94.

Artiles, A. (2003). Special education's changing identity: Paradoxes and dilemmas in views of culture and space. Harvard Educational Review, 73, 164-202.

Artiles, A., Rueda, R., Salazar, J. J., Higareda, I. (2005). Within-group diversity in minority disproportionate representation: English language learners in urban school districts. Exceptional Children, 71, 283-300.

August, D., Francis, D., Han-Ya, A. H., Snow, C. (2006). Assessing reading comprehension in bilinguals. The Elementary School Journal, 107(2), 221-238.

August, D., Shanahan, T. (Eds.). (2008). Developing reading and writing in second-language learners: Lessons from the report of the National Literacy Panel on language-minority children and youth. New York, NY: Routledge.

Bernhard, J., Cummins, J., Campoy, I., Ada, A. F., Winsler, A., Bleiker, C. (2006). Identity texts and literacy development among preschool English language learners: Enhancing learning opportunities for children at risk for learning disabilities. Teachers College Record, 108, 2380-2405.

Borman, G., Dowling, M. (2010). Schools and inequality: A multilevel analysis of Coleman's equality of educational opportunity data. Teachers College Record, 112, 1201-1246. 
Boscardin, M. L. (2005). The administrative role in transforming secondary schools to support inclusive evidence-based practices. American Secondary Education, 33(3), 21-32.

Brisk, M. E. (2006). Bilingual education: From compensatory to quality schooling. Mahwah, NJ: Lawrence Erlbaum.

Brooks, J. S., Jean-Marie, G., Normore, A., Hodgins, D. (2007). Distributed leadership for social justice: Exploring how influence and equity are stretched over an urban high school. Journal of School Leadership, 17, 378-408.

Bryk, A., Sebring, P. B., Allensworth, E., Luppescu, S., Easton, J. (2010). Organizing schools for improvement: Lessons from Chicago. Chicago, IL: University of Chicago Press.

Bunch, G. (2006). "Academic English" in the 7th grade: Broadening the lens, expanding access. Journal of English for Academic Purposes, 5, 284-301.

Bunch, G. (2010). Preparing mainstream secondary content-area teachers to facilitate English language learners' development of academic language. National Society for the Study of Education, 109, 351-383.

Bustamante, R., Nelson, J., Onwuegbuzie, A. J. (2009). Assessing schoolwide cultural competence: Implications for school leadership preparation. Educational Administration Quarterly, 45, 793827.

Callahan, R. (2005). Tracking and high school English learners: Limiting opportunity to learn. American Educational Research Journal, 42, 305-328.

Callahan, R., Wilkinson, L., Muller, C., Frisco, M. (2009). ESL placement and schools. Educational Policy, 23, 355-384.

Cirino, P., Pollard-Durodola, S., Foorman, B., Carlson, C., Francis, D. (2007). Teacher characteristics, classroom instruction, and student literacy and language outcomes in bilingual kindergartners. Elementary School Journal, 107, 342-364.

Cooper, C. W., Christie, C. (2005). Evaluating parent empowerment: A look at the potential of social justice evaluation in education. Teachers College Record, 107, 2248-2274.

Coyoca, A. M., Lee, J. S. (2009). A typology of language-brokering events in dual-language immersion classrooms. Bilingual Research Journal, 32, 260-279.

Curran, M. E. (2003). Linguistic diversity and classroom management. Theory Into Practice, 42, 334-340.

Davison, C. (2006). Collaboration between ESL and content teachers: How do we know when we are doing it right? International Journal of Bilingual Education and Bilingualism, 9, 454-475.

de Jong, E. J. (2002). Effective bilingual education: From theory to academic achievement in two-way bilingual program. Bilingual Research Journal, 26, 65-84.

de Jong, E. J. (2004). Second language proficiency development in a two-way and developmental bilingual program. NABE Journal of Research and Practice, 2, 57-77.

de Jong, E. J. (2006). Integrated bilingual education: An alternative approach. Bilingual Research Journal, $30,23-44$.

Diaz, R. M. (1983). Thought and two languages: The impact of bilingualism on cognitive development. Review of Research in Education, 10, 23-54.

Drago-Severson, E. (2007). Helping teachers learn: Principals as professional development leaders. Teachers College Record, 109, 70-125.

Fergus, E. (2009). Understanding Latino students' schooling experiences: The relevance of skin color among Mexican and Puerto Rican high school students. Teachers College Record, 111, 339-375. 
Foulger, T., Jimenez-Silva, M. (2007). Enhancing the writing development of English language learners: Teacher perceptions of common technology in project-based learning. Journal of Research in Childhood Education, 22, 109-124.

Frankenberg, E. (2008). The segregation of American teachers. Education Policy Analysis Archives, 17, 1142.

Frattura, E., Capper, C. (2007). Leadership for social justice in practice: Integrated comprehensive services for all learners. Thousand Oaks, CA: Corwin Press.

Fry, R. (2007). How far behind in math and reading are English language learners? Washington, DC: Pew Hispanic Center.

Gandara, P., Moran, R., Garcia, E. (2004). Legacy of Brown: Lau and language policy in the United States. Review of Research in Education, 28, 27-46.

Gandara, P., Rumberger, R., Maxwell-Jolly, J., Callahan, R. (2003). English learners in California schools: Unequal resources, unequal outcomes. Educational Policy Analysis Archives, 11(36), 1-54.

Garcia, E., Arias, M. B., Murri, N. J. H., Serna, C. (2010). Developing responsive teachers: A challenge for a demographic reality. Journal of Teacher Education, 61, 132-142.

Garcia, E., Cuellar, D. (2006). Who are these linguistically and culturally diverse students? Teachers College Record, 108, 2220-2246.

Garcia, E., Jensen, B. (2007). Language development and early education of young Hispanic children in the United States. Tempe, AZ: National Task Force on Early Childhood Education for Hispanics.

Gersten, R., Baker, S. (2000). What we know about effective instructional practices for English-language learners. Exceptional Children, 66, 454-470.

Goldenberg, C., Rueda, R., August, D. (2008). Sociocultural contexts and literacy development. In August, D., Shanahan, T. (Eds.), Developing reading and writing in second-language learners: Lessons from the report of the National Literacy Panel on language-minority children and youth (pp. 95129). New York: Routledge.

Gonzalez, N., Rosi, A., Civil, M., Moll, L. (2001). Bridging funds of distributed knowledge: Creating zones of practices in mathematics. Journal of Education for Students Placed at Risk, 6, 115-132.

Gottlieb, M. (2004). English language proficiency standards for English language learners in kindergarten through grade 12. Madison, WI: WIDA Consortium.

Guo, Y. (2009). Communicating with parents across cultures: An investigation of an ESL parents' night. Journal of Educational Thought, 43, 171-190.

Gutierrez, P. (2002). In search of bedrock: Organizing for success with diverse needs children in the classroom. Journal of Latinos and Education, 1, 49-64.

Gutierrez, R. (2002). Beyond essentialism: The complexity of language in teaching mathematics to Latina/o students. American Educational Research Journal, 39, 1047-1088.

Haas, E., Gort, M. (2009). Demanding more: Legal standards and best practices for English language learners. Bilingual Research Journal, 32, 115-135.

Haley, M. H. (2004). Learner-centered instruction and the theory of multiple intelligences with second language learners. Teachers College Record, 106, 163-180.

Hallinger, P., Heck, R. (1998). Exploring the principal's contribution to school effectiveness: 1980-1995. School Effectiveness and School Improvement, 9, 157-191.

Harper, C., de Jong, E. J. (2009). English language teacher expertise: The elephant in the room. Language and Education, 23, 137-151. 
Hawkins, M. R. (2004). Researching English language and literacy development in schools. Educational Researcher, 33(3), 14-25.

Hernandez, D., Denton, N., Macartney, S. (2009). School-age children in immigrant families: Challenges and opportunities for America's schools. Teachers College Record, 111, 616-658.

Janzen, J. (2008). Teaching English language learners in the content areas. Review of Educational Research, 78, 1010-1038.

Jepsen, C. (2010). Bilingual education and English proficiency. Education Finance and Policy, 5, 200-227.

Johnson, R., La Salle, R. A. (2010). The wallpaper effect: Data strategies to uncover and eliminate hidden inequities. Thousand Oaks, CA: Corwin Press.

Kennedy, M. (2010). Attribution error and the quest for teacher quality. Educational Researcher, 39, 591-598.

Kieffer, M., Lesaux, N., Rivera, M., Francis, D. (2009). Accommodations for English language learners taking large-scale assessments: A meta-analysis on effectiveness and validity. Review of Educational Research, 79, 1168-1201.

Kim, Y.-H., Jang, E. E. (2009). Differential functioning of reading subskills on the OSSLT for L1 and ELL students: A multidimensionality model-based DBF/DIF approach. Language Learning, 59(4), 825865.

Lara-Alecio, R., Tong, F., Irby, B. J., Mathes, P. (2009). Teachers' pedagogical differences during ESL block among bilingual and English-immersion kindergarten classrooms in a randomized trial study. Bilingual Research Journal, 32, 77-100.

Lee, O. (2003). Equity for linguistically and culturally diverse students in science education: A research agenda. Teachers College Record, 105, 465-489.

Lee, O. (2004). Teacher change in beliefs and practices in science and literacy instruction with English language learners. Journal of Research in Science Teaching, 41, 65-93.

Lee, O., Luykx, A. (2005). Dilemmas in scaling up innovations in elementary science instruction with nonmainstream students. American Educational Research Journal, 42, 411-438.

Lee, O., Mahotiere, M., Salinas, A., Penfield, R. D., Maerten-Rivera, J. (2009). Science writing achievement among English language learners: Results of three-year intervention in urban elementary schools. Bilingual Research Journal, 32, 153-167.

Lee, S.-K. (2007). Effects of textual enhancement and topic familiarity on Korean EFL students' reading comprehension and learning of passive form. Language Learning, 57, 87-118.

Lesaux, N., Kieffer, M., Faller, S., Kelley, J. (2010). The effectiveness and ease of implementation of an academic vocabulary intervention for linguistically diverse students in urban middle schools. Reading Research Quarterly, 45, 196-228.

López, F. (2010). Identity and motivation among Hispanic English language learners in disparate educational contexts. Education Policy Analysis Archives, 18(16), 1-33.

Lucas, T., Henze, R., Donato, R. (1990). Promoting the success of Latino language-minority students: An exploratory study of six high schools. Harvard Educational Review, 60, 315-340.

Lucas, T., Villegas, A. M., Freedson-Gonzalez, M. (2008). Linguistically responsive teacher education: Preparing classroom teachers to teach English language learners. Journal of Teacher Education, 59, 361-373.

MacSwan, J., Rolstad, K. (2005). Modularity and the facilitation effect: Psychological mechanisms of transfer in bilingual students. Hispanic Journal of Behavioral Sciences, 27, 224-243. 
MacSwan, J., Rolstad, K. (2006). How language proficiency tests mislead us about ability: Implications for English language learner placement in special education. Teachers College Record, 108, 23042328.

Marks, H., Louis, K. S. (1999). Teacher empowerment and the capacity for organizational learning. Educational Administration Quarterly, 35, 707-750.

Marshall, C., Oliva, M. (2006). Building the capacities of social justice leaders. In Marshall, C., Oliva, M. (Eds.), Leadership for social justice: Making revolutions in education (pp. 1-15). Boston, MA: Pearson.

McKenzie, K. B., Scheurich, J. J. (2004). Equity traps: A useful construct for preparing principals to lead schools that are successful with racially diverse students. Educational Administration Quarterly, 40, 601-631.

McMahon, S., Wernsman, J., Rose, D. (2009). The relation of classroom environment and school belonging to academic self-efficacy among urban fourth- and fifth-grade students. Elementary School Journal, 109, 267-281.

Medina, M. (1988). Hispanic apartheid in American public education. Educational Administration Quarterly, 24, 336-349.

Meyer, L. M. (2000). Barriers to meaningful instruction for English learners. Theory Into Practice, 39, 228-236.

Mora, J. K., Wink, J., Wink, D. (2001). Dueling models of dual language instruction: A critical review of the literature and program implementation guide. Bilingual Research Journal, 24, 435-460.

National Center for Education Statistics . (2010). Status and trends in the education of racial and ethnic minorities. Washington, DC: U.S. Department of Education, Institute of Education Sciences.

Olivos, E. M., Ochoa, A. M. (2008). Reframing due process and institutional inertia: A case study of an urban school district. Equity \& Excellence in Education, 41(3), 279-292.

Olsen, L. (2010). Reparable harm: Fulfilling the unkept promise of educational opportunity for California's long term English learners. Long Beach: Californians Together.

Olson, K., Jimenez-Silva, M. (2008). The campfire effect: A preliminary analysis of preservice teachers' beliefs about teaching English language learners after state-mandated endorsement courses. Journal of Research in Childhood Education, 22, 246-260.

Orellana, M., Reynolds, J. (2008). Cultural modeling: Leveraging bilingual skills for school paraphrasing tasks. Reading Research Quarterly, 43, 48-65.

Osterman, K. (2000). Students' need for belonging in the school community. Review of Educational Research, 70, 323-367.

Ovando, C. (2003). Bilingual education in the United States: Historical development and current issues. Bilingual Research Journal, 27, 1-25.

Parks, A. N. (2010). Explicit versus implicit questioning: Inviting all children to think mathematically. Teachers College Record, 112, 1871-1896.

Pawan, F. (2008). Content-area teachers and scaffolded instruction for English language learners. Teaching and Teacher Education, 24, 1450-1462.

Pianta, R., Hamre, B. (2009). Conceptualization, measurement, and improvement of classroom processes: Standardized observation can leverage capacity. Educational Researcher, 38, 109119. 
Popay, J., Roberts, H., Sowden, A., Petticrew, M., Arai, L., Rodgers, M., .. . Duffy, S. (2006). Guidance on the conduct of narrative synthesis in systematic reviews. London, UK: Economic and Social Research Council.

Reeves, J. (2004). "Like everybody else": Equalizing educational opportunity for English language learners. TESOL Quarterly, 38, 43-66.

Reeves, J. (2006). Secondary teacher attitudes toward including English-language learners in mainstream classrooms. Journal of Educational Research, 99, 131-142.

Riojas-Cortez, M. (2001). Preschoolers' funds of knowledge displayed through sociodramatic play episodes in a bilingual classroom. Early Childhood Education Journal, 29, 35-40.

Ro, Y., Cheatham, G. (2009). Biliteracy and bilingual development in a second-generation Korean child: A case study. Journal of Research in Childhood Education, 23, 290-308.

Robertson, C. (2011). After ruling, Hispanics flee an Alabama town. New York Times. Retrieved from http://www.nytimes.com/2011/10/04/us/after-ruling-hispanics-flee-an-alabamatown.html?_r=1\&scp=4\&sq=alabama\%20immigration\%20lawst=cse

Rodgers, M., Sowden, A., Petticrew, M., Arai, L., Roberts, H., Britten, N., Popay, J. (2009). Testing methodological guidance on the conduct of narrative synthesis in systematic reviews. Evaluation, 15, 49-74.

Rodriguez, D. (2009). Meeting the needs of English language learners with disabilities in urban settings. Urban Education, 44, 452-464.

Rolstad, K., Mahoney, K., Glass, G. V. (2005). The big picture: A meta-analysis of program effectiveness research on English language learners. Educational Policy, 19, 572-594.

Rumberger, R., Palardy, G. (2005). Does segregation still matter? The impact of student composition on academic achievement in high school. Teachers College Record, 107(9), 1999-2045.

Saenz, L., Fuchs, D., Fuchs, L. S. (2005). Peer-assisted learning strategies for English language learners with learning disabilities. Exceptional Children, 71, 231-247.

Salomone, R. (2010). True American: Language, identity, and the education of immigrant children. Cambridge, MA: Harvard University Press.

Scanlan, M., Palmer, D. (2009). Race, power, and (in)equity within two-way immersion settings. Urban Review, 41(5), 391-415.

Schleppegrell, M. (2007). The linguistic challenges of mathematics teaching and learning: A research review. Reading \& Writing Quarterly, 23, 139-159.

Senesac, B. V. K. (2002). Two-way bilingual immersion: A portrait of quality schooling. Bilingual Research Journal, 26, 1-17.

Silverman, R. D. (2007). Vocabulary development of English-language and English-only learners in kindergarten. Elementary School Journal, 107, 365-383.

Skrla, L., Scheurich, J. J., Garcia, J., Nolly, G. (2004). Equity audits: A practical leadership tool for developing equitable and excellent schools. Educational Administration Quarterly, 40, 133-161.

Slavin, R. E., Cheung, A. (2005). A synthesis of research on language of reading instruction for English language learners. Review of Educational Research, 75, 247-284.

Sleeter, C. (2001). Preparing teachers for culturally diverse schools: Research and the overwhelming presence of whiteness. Journal of Teacher Education, 52, 94-106.

Spillane, J., Halverson, R., Diamond, J. (2001). Investigating school leadership practice: A distributed perspective. Educational Researcher, 30, 23-28. 
Spillane, J., Halverson, R., Diamond, J. (2004). Towards a theory of leadership practice: A distributed perspective. Journal of Curriculum Studies, 36, 3-34.

Spycher, P. (2009). Learning academic language through science in two linguistically diverse kindergarten classes. Elementary School Journal, 109, 359-379.

Theoharis, G. (2007). Social justice educational leaders and resistance: Toward a theory of social justice leadership Educational Administration Quarterly, 43, 221-258.

Tong, F., Irby, B. J., Lara-Alecio, R., Mathes, P. (2008). English and Spanish acquisition by Hispanic second graders in developmental bilingual programs: A 3-year longitudinal randomized study. Hispanic Journal of Behavioral Sciences, 30, 500-529.

Tong, F., Irby, B. J., Lara-Alecio, R., Yoon, M. (2010). Hispanic English learners' responses to longitudinal English instructional intervention and the effect of gender: A multilevel analysis. Elementary School Journal, 110, 542-566.

U.S. Department of Education . (n.d.). NCLB testing: Frequently asked questions. Retrieved from http://www2.ed.gov/nclb/accountability/ayp/testing-faq.html\#5

Villegas, A. M., Lucas, T. (2002). Preparing culturally responsive teachers: Rethinking the curriculum. Journal of Teacher Education, 53, 20-32.

Villegas, A. M., Lucas, T. (2007). The culturally responsive teacher. Educational Leadership, 64, 28-33.

Wallace Foundation . (2008). Becoming a leader: Preparing school principals for today's schools. New York, NY: Author.

Waters, T., Grubb, S. (2004). Leading schools: Distinguishing the essential from the important. Denver, CO: Mid-continent Research for Education and Learning.

Wiley, T., Wright, W. (2004). Against the undertow: Language-minority education policy and politics in the "age of accountability." Educational Policy, 18, 142-168.

Zehr, M. A. (2010). Boston settles with federal officials in ELL probe. Education Week, 30(7). Retrieved from http://www.edweek.org/ew/articles/2010/10/01/07boston.h30.html?tkn=TOPFqjZHNi8h0Xgr8 hlqd5NwyGP301QFaU7o\&cmp=clp-edweekon10/12/2010 